\title{
Correction to: Multiple levers for overcoming the recalcitrance of lignocellulosic biomass
}

\author{
Evert K. Holwerda ${ }^{1,2^{*}}$, Robert S. Worthen ${ }^{1,2}$, Ninad Kothari ${ }^{2,3}$, Ronald C. Lasky ${ }^{1}$, Brian H. Davison ${ }^{2,4}$, \\ Chunxiang Fu' ${ }^{2,5}$, Zeng-Yu Wang ${ }^{2,5}$, Richard A. Dixon ${ }^{2,6}$, Ajaya K. Biswal ${ }^{2,7}$, Debra Mohnen ${ }^{2,7}$, Richard S. Nelson ${ }^{2,5}$, \\ Holly L. Baxter ${ }^{2,8}$, Mitra Mazarei ${ }^{2,8}$, C. Neal Stewart Jr. ${ }^{2,8}$, Wellington Muchero ${ }^{2,4}$, Gerald A. Tuskan ${ }^{2,4}$, \\ Charles M. Cai ${ }^{2,3}$, Erica E. Gjersing ${ }^{2,9}$, Mark F. Davis ${ }^{2,9}$, Michael E. Himmel ${ }^{2,9}$, Charles E. Wyman ${ }^{2,3}$, Paul Gilna ${ }^{2,4}$ \\ and Lee R. Lynd ${ }^{1,2^{*}}$
}

\section{Correction to: Biotechnol Biofuels (2019) 12:15 https://doi.org/10.1186/s13068-019-1353-7}

Following publication of the original article [1], the authors reported the omission of one author name.

C. Neal Stewart Jr. was not included as an author during production process. The publishers apologise for this error. The full author list is given in this correction article. The original article [1] has been updated.

\begin{abstract}
Author details
${ }^{1}$ Thayer School of Engineering, Dartmouth College, 14 Engineering drive, Hanover, NH 03755, USA. ${ }^{2}$ BioEnergy Science Center, Oak Ridge National Laboratory, Oak Ridge, TN 37831, USA. ${ }^{3}$ Department of Chemical and Environmental Engineering and Center for Environmental Research and Technology, Bourns College of Engineering, University of California Riverside, Riverside, CA 92521, USA. ${ }^{4}$ Biosciences Division, Oak Ridge National Laboratory, Oak Ridge, TN 37831, USA. ${ }^{5}$ Genomics Division, Noble Research Institute, Ardmore, OK 73401, USA. ${ }^{6}$ Department of Biological Sciences, University of North Texas, Denton, TX 76203, USA. ${ }^{7}$ Complex Carbohydrate Research Center, University of Georgia, Athens, GA 30602, USA. ${ }^{8}$ Department of Plant Sciences, University of Tennessee at Knoxville, Knoxville, TN 37996, USA. ${ }^{9}$ Bioenergy Science and Technology, National Renewable Energy Laboratory, Golden, CO 80401, USA.
\end{abstract}

The original article can be found online at https://doi.org/10.1186/s1306 8-019-1353-7.

\section{Publisher's Note}

Springer Nature remains neutral with regard to jurisdictional claims in published maps and institutional affiliations.

Received: 5 October 2018 Accepted: 4 January 2019

Published online: 09 February 2019

\section{Reference}

1. Holwerda EK, Worthen RS, Kothari N, Lasky RC, Davison BH, Fu C, Wang Z-Y, Dixon RA, Biswal AK, Mohnen D, Nelson RS, Baxter HL, Mazarei M, Stewart CN Jr., Muchero W, Tuskan GA, Cai CM, Gjersing EE, Davis MF, Himmel ME, Wyman CE, Gilna P, Lynd LR. Multiple levers for overcoming the recalcitrance of lignocellulosic biomass. Biotechnol Biofuels. 2019;12:15. https://doi.org/10.1186/s13068-019-1353-7.

*Correspondence: evert.k.holwerda@dartmouth.edu;

Lee.R.Lynd@dartmouth.edu

${ }^{1}$ Thayer School of Engineering, Dartmouth College, 14 Engineering drive,

Hanover, NH 03755, USA

Full list of author information is available at the end of the article 